Jurnal Agrotech 9 (2) 60-65

e-ISSN : 2621-7236

p-ISSN : 1858-134X

\title{
ANALISIS KELAYAKAN USAHA PENGGILINGAN PADI DI DESA LAKATAN KECAMATAN GALANG KABUPATEN TOLITOLI (STUDI KASUS PENGGILINGAN "CAHAYA UMMUL")
}

\section{FEASIBILITY ANALYSIS OF RICE MILLING BUSINESS IN LAKATAN VILLAGE KECAMATAN GALANG TOLITOLI DISTRICT (CASE STUDY OF "CAHAYA UMMUL" MILLING)}

\author{
Nur Hikmah ${ }^{1 *}$ Juria $^{1}$ \\ ${ }^{1}$ Program Studi Agribisnis, Sekolah Tinggi Ilmu Pertanian Mujahidin Toli-Toli, \\ Jl. Dr. Samratulangi No. 51, Tuweley Tolitoli Sulawesi Tengah
}

\begin{abstract}
ABSTRAK
Penelitian ini bertujuan untuk mengetahui tingkat Kelayakan Usaha Penggilingan "Cahaya Ummul". Hasil penelitian menunjukkan bahwa analisis payback period atau lama waktu investasi yang akan dikembalikan terjadi pada waktu 9 tahun 3 bulan, analisis NPV atau arus kas yang diperkirakan pada masa yang akan datang yang didiskontokan pada saat ini yaitu sebesar 14\% dengan jumlah NPV sebesar 232.480.306 > 0 (positif), analisis Net B/C yaitu nilai perbandingan antara jumlah PV net benefit yang positif dengan jumlah PV net benefit yang negatif didapatkan nilai sebesar 1,19>1, dan analisis IRR yaitu tingkat efisien dari suatu investasi sebesar $21,016 \%$ dengan suku bunga sebesar $14 \%$ saat dilakukan evaluasi. Jadi usaha ini dinyatakan layak untuk diusahakan.
\end{abstract}

Kata kunci : analisis kelayakan usaha, penggilingan padi.

\section{ABSTRACT}

This study aims to determine the level of Feasibility of "Cahaya Ummul " Milling. Determination of the object and location of the study was intentionally determined. The results showed that the analysis of the payback period or the length of time the investment will be returned occurred in 9 years 3 months, NPV analysis or estimated future cash flows discounted at $14 \%$ with a total NPV of 232,480,306 > 0 (positive), $N e t B / C$ analysis is the value of the ratio between the number of positive net benefit $P V s$ with the number of negative net benefit PVs obtained a value of 1.19>1, and the IRR analysis of the efficient level of an investment of 21,016\% with an interest rate of $14 \%$ when evaluating. So this business was declared worth the effort.

Keywords: feasibility business analysis, rice milling

\section{Pendahuluan}

Penanganan pascapanen tanaman padi merupakan salah satu faktor penting dalam menentukan kualitas dan kuantitas beras yang dihasilkan. Teknologi pascapanen yang tepat guna mutlak diperlukan karena berkaitan dengan jumlah dan mutu komoditas. Penerapan teknologi ini akan

\footnotetext{
*) Penulis Korespondensi

E-mail: nhikmah.bakri@gmail.com

Telp: +62-82290423381
}

mendorong terciptanya komoditas yang lebih beragam, bermutu baik dan tersedia di setiap tempat dan waktu. Salah satu aspek penting penanganan pasca panen padi adalah penggilingan padi. Proses penggilingan ini penting karena turut menentukan kualitas dan kuantitas beras yang di hasilkan.

Penggilingan padi merupakan pusat pertemuan antara produksi, pascapanen, pengelolaan dan pemasaran gabah atau beras sehingga merupakan mata rantai penting dalam suplai beras nasional yang dituntut dapat 
Jurnal Ogrotech 9 (2) 60-65

memberikan kontribusi dalam penyediaan beras, baik dari segi kualitas maupun kuantitas untuk mendukung ketahanan pangan nasional. Proses usaha penggilingan padi mempunyai harapan yang cukup cerah untuk masa-masa yang akan datang karena kebutuhan akan beras masih cukup tinggi dan melalui peningkatan luas lahan, produktifitas, perbaikan penanganan pascapanen khususnya usaha penggilingan padi dan pemasaran beras baik dalam negeri maupun luar negeri. (Ditjen Bina Pengolahan dan Pemasaran Hasil Pertanian, 2009).

Masalah utama dalam penanganan pascapanen padi yang sering dialami oleh petani adalah tingginya kehilangan hasil selama pascapanen. Kegiatan pascapanen meliputi proses pemanenan padi, penyimpanan padi, pengeringan gabah, dan penggilingan gabah hingga menjadi beras. Besarnya kehilangan pascapanen terjadi kemungkinan dikarenakan sebagian besar petani masih menggunakan cara-cara tradisional atau meskipun sudah menggunakan peralatan mekanis tetapi proses penanganan pascapanennya masih belum baik dan besar sehingga pemerintah perlu lebih sosialisasikan penanganan pascapanen yang baik. (Ritonga, $d k k$ 2008).

Kabupaten Tolitoli memiliki mesin penggiling padi sebanyak 254 unit tersebar di sepuluh Kecamatan yakni; Kecamatan Dampal Selatan 51 unit, Kecamatan Dampal Utara 8 unit, Kecamatan Ogodeide 18 unit, Kecamatan Dondo 25 unit, Kecamatan Basidondo 12 unit, Kecamatan Lampasio 34 unit, Kecamatan Baolan 3 unit, Kecamatan Galang 62 unit, Kecamatan Dakopemean 13 unit, Kecamatan Tolitoli Utara 28 unit (BPS Tolitoli, 2010) akan tetapi jumlah tersebut tidak semuanya aktif disebabkan karena persaingan yang cukup ketat antar sesama usaha penggilingan padi.

\section{Metode Penelitian}

Untuk memgetahui kelayakan usaha penggilingan padi dapat digunakan analisis kelayakan usaha dengan rumus dan persamaan sebagai berikut:

\section{Net Present value (NPV)}

Net present value adalah nilai pengembalian modal yang diinvestasikan dan memberikan tingkat pengembalian yang diperlukan atas modal tersebut. Nilai NPV diperoleh dengan Rumus:
e-ISSN : 2621-7236

p-ISSN : 1858-134X

$$
N P V=\sum_{t=0}^{t=n}(B t-C t)(D F)
$$

(Choliq, dkk 1999)

Dimana : $\mathrm{Bt}=$ benefit pada Tahun ke-t

$\mathrm{Ct}=$ cost pada Tahun ke-t

$\mathrm{DF}=$ discount faktor

I = tingkat bunga yang berlaku

$\mathrm{N}$ = lamanya periode waktu

Kriteria pengambilan keputusan:

1) NPV >0, proyek layak untuk dikembangkan dan menguntungkan.

2) $\mathrm{NPV}=0$, proyek tidak untung dan tidak rugi.

3) NPV < 0, proyek tidak layak untuk dikembangkan dan tidak menguntungkan.

\section{Net Benefit Of cost Ratio (Net B/C)}

Net Benefit Of cost Ratio merupakan perbandingan antara jumlah NPV positife dan NPV negatif yang menunjukan gambaran berapa kali lipat benefit akan diperoleh dari cost yang dikeluarkan. Rumusnya (Choliq, dkk 1999):

NET B/C $=\frac{\sum_{\mathrm{t}=0}^{\mathrm{t}=\mathrm{n}} \mathrm{NPV}^{+}}{\sum_{\mathrm{t}=0}^{\mathrm{t}=\mathrm{n}} \mathrm{NPV}^{-}}$

Dimana: $\mathrm{NPV}_{1}=$ net present value positif

$\mathrm{NPV}_{2}=$ net present value negatif

$n \quad=$ lamanya periode waktu

\section{Internal Rate Of Return (IRR)}

Internal Rate Of Return (IRR) merupakan salah satu metode untuk mengukur tingkat investasi. Rumusnya (Choliq, dkk 1999):

$$
I R R=i^{\prime}+\frac{N P V_{\prime}}{N P V_{\prime}-N P V^{\prime \prime}}\left(i^{\prime \prime}-i^{\prime}\right)
$$

Dimana:

$i^{\prime}=$

tingkat bunga (DF)pertama diperoleh dari NPV ${ }^{-}$ $i^{\prime \prime}=$

tingkat bunga (DF)pertama diperoleh dari $\mathrm{NPV}^{+}$ Kriteria pengambilan keputusan :

1) IRR > bunga modal, layak untuk diusahakan dan menguntungkan

2) IRR < bunga modal, tidak layak untuk diusahakan dan tidak menguntungkan 


\section{Hasil dan Pembahasan}

\section{a. Biaya Usaha}

Biaya adalah salah satu faktor penentu kelancaran menjalankan suatu usaha. Hal ini disebabkan oleh besarnya tingkat produktivitas hasil panen tergantung berapa besar biaya yang dikeluarkan selama proses produksi berjalan dan besarnya biaya yang dikeluarkan untuk menjalankan suatu usaha penggilingan padi .

\section{Biaya Investasi}

Biaya investasi merupakan biaya yang dikeluarkan untuk jangka waktu tertentu agan mendapatkan bayaran dimasa depan atas konvensasi biaya yang ditanamkan. Biaya investasi umumnya merupakan biaya yang biasa dipakai dalam jangka panjang. Usaha Penggilingan Padi biaya investasi yang dibutuhkan biasanya digunakan untuk biaya pengadaan vertical dryer, pengadaan mesin giling, pengadaan mesin jahit karung dan pengadaan alat lainya seperti karung gabah, benang, spidol dan timbangan.

Tabel 1. Rata-rata biaya investasi yang dikeluarkan pengusaha penggilingan padi "Cahaya Ummul" di Desa Lakatan Kecamatan Galang Kabupaten Tolitoli Tahun 2017.

\begin{tabular}{|c|c|c|c|}
\hline No & Jenis Investasi & $\begin{array}{c}\text { Jumlah } \\
\text { (Unit) }\end{array}$ & $\begin{array}{l}\text { Nilai } \\
\text { (Rp) }\end{array}$ \\
\hline \multirow[t]{4}{*}{1.} & Bangunan & & \\
\hline & - Gedung & 2 unit & 80.000 .000 \\
\hline & - Gudang & 1 unit & 20.000 .000 \\
\hline & - Lantai jemur & 3 unit & 60.000 .000 \\
\hline \multirow[t]{3}{*}{2.} & Mesin giling & & \\
\hline & - Double & 1 unit & 488.000 .000 \\
\hline & Ratna Gisel & 1 unit & 30.000 .00 \\
\hline \multirow[t]{2}{*}{3.} & - Huller & 2 unit & 7.000 .000 \\
\hline & Nyanmar & 2 unit & 5.000 .000 \\
\hline \multirow[t]{2}{*}{4.} & Mesin jait karung & & \\
\hline & Timbangan & 1 unit & 300.000 .000 \\
\hline \multirow[t]{2}{*}{5.} & $\begin{array}{l}\text { Mobil } \\
\text { - } \text { Truck } \\
- \text { Pick up }\end{array}$ & 2 unit & 200.000 .000 \\
\hline & Total & 15 unit & 1.190 .000 .000 \\
\hline
\end{tabular}

Sumber: Data Primer Setelah diolah, 2018

\section{Biaya Operasional}

Biaya Operasional adalah biaya yang dibutuhkan untuk pelaksanaan suatu usaha mempunyai sifat yang jumlahnya dapat berubahubah sesuai kebutuhan usaha tersebut, biaya ini harus dikeluarkan secara rutin sepanjang usia ekonomis suatu proyek. Usaha Penggilingan Padi yang termaksud biaya operasional adalah biaya bahan bakar dan upah tenaga kerja.

\section{Biaya Pemeliharaan}

Usaha Penggilingan Padi dengan menggunakan alat penggiling padi ini yang dimaksud dengan biaya pemeliharaan yaitu semua yang diperlukan untuk memelihara peralatan dan mesin agar tetap berfungsi sesuai umur ekonomisnya.

\section{Kenaikan Biaya Usaha}

Kenaikan biaya usaha dapat didefinisikan sebagai selisih antara biaya usaha yang baru dengan biaya usaha yang lama. Kenaikan biaya biasanya dihitung karena adanya tambahan investasi pada usaha tersebut, tambahan investasi ini tambahan biaya investasi ini dapat berupa gedung, gudang, mesin dan peralatan yang digunakan dan dapat berupa penggantian peralatan tertentu.

\section{b. Benefit}

Pada perencanaan antara evaluasi proyek penerimaan disebut Benefit. Benefit adalah perkalian antara jumlah produksi dengan harga yang telah dipresent valuekan atau setelah dikalikan dengan Faktor Diskonto sesuai dengan interst rate yang berlaku.

\section{c. Proyeksi Rugi-Laba}

Laporan rugi-laba (Balance sheet) adalah laporan yang menunjukan jumlah pendapatan dan biaya-biaya yang dikeluarkan dalam suatu periode tertentu (Kasmir dan Jakfar, 2004). Proyeksi laporan rugi-laba menggambarkan besarnya pendapatan yang diperoleh pada suatu period eke periode berikutnya. Kemudian juga akan tergambar jenis-jenis biaya yang dikeluarkan berikut jumlahnya dalam periode yang sama. Laporan ini menunjukan tentang kondisi keuangan perusahaan apakah terdapat keuntungan atau kerugian dalam suatu periode atau beberapa periode.

\section{d. Kelayakan Usaha}

Studi kelayakan pada hakikatnya adalah untuk mendapatkan layak atau tidak layaknya suatu usaha, dengan kata lain studi kelayakan harus dapat memutuskan apakah suatu usaha perlu diteruskan atau tidak. Untuk mengetahui tingkat keuntungan dan kelayakan usaha yang dijalankan, maka dilakukan pendekatan analisis sebagai berikut. 
Jurnal Ogrotech 9 (2) 60-65

\section{Cash Flow}

Perputaran uang tunai dalam satu kali proses produksi usaha penggilingan padi "Cahaya Ummul"

Tabel 2. Analisis Cash Flow Penggilingan Padi "Cahaya Ummul"

\begin{tabular}{crrr}
\hline Thn & \multicolumn{1}{c}{ Benefit } & \multicolumn{1}{c}{ Cost } & \multicolumn{1}{c}{ Net Benefit } \\
\hline 0 & & $(1.190 .000 .000)$ & $(1.190 .000 .000)$ \\
1 & 436.275 .000 & 53.454 .560 & 382.820 .440 \\
2 & 455.250 .000 & 55.618 .000 & 399.632 .000 \\
3 & 469.629 .000 & 55.669 .500 & 413.959 .500 \\
4 & 489.054 .000 & 70.503 .800 & 418.550 .200 \\
5 & 542.193 .000 & 95.621 .500 & 446.571 .500 \\
\hline Jumlah & 2.392 .401 .000 & 859.132 .640 & 871.533 .640 \\
\hline \multicolumn{4}{l}{ Sumber: Data Primer Setelah Diolah,2018 }
\end{tabular}

Berdasarkan Tabel 2. total Benefit usaha penggilingan padi "Cahaya Ummul" sebesar Rp.2.392.401.000, dengan total Cost sebesar Rp. 859.132.640, sehingga jumlah Net Benefit masih sebesar Rp.871.533.640,

\section{Net Present Value (NPV)}

Net Present Value merupakan metode yang digunakan untuk memperhitungkan nilai waktu dari uang atas nilai suatu investasi. Tingkat bunga yang ditetapkan pada perhitungan ini adalah 10\% dengan asumsi bahwa nilai aliran kas operasional usaha dianggap sebagai bahan dalam perhitungan proyeksi kelayakan usaha di masa akan datang. Apabila nilai sekarang penerimaan kas bersih dimasa yang akan datang lebih besar dari pada nilai sekarang investasi, maka usaha tersebut dikatakan layak atau menguntungkan sedangkan apabila lebih kecil dari nilai sekarang maka usaha dianggap tidak menguntungkan.

Tabel 3. Perhitungan NPV Selama 5 Tahun Pada Usaha Penggilingan Padi Cahaya Ummul

\begin{tabular}{crrr}
\hline Tahun & \multicolumn{1}{c}{ Net Benefit } & DF (14\%) & \multicolumn{1}{c}{ PV Net Benefit } \\
\hline 0 & $(1.190 .000 .000)$ & 1.000000 & $(1.190 .000 .000)$ \\
1 & 382.820 .440 & 0.877193 & $335.807 .410,2$ \\
2 & 399.632 .000 & 0.769468 & $307.511 .229,1$ \\
3 & 413.959 .500 & 0.674972 & $279.411 .071,6$ \\
4 & 418.550 .200 & 0.592080 & $247.815 .202,4$ \\
5 & 446.571 .500 & 0.519369 & $231.935 .393,3$ \\
\hline Iumlah & 871.533 .640 & & 232.480 .306 \\
\hline
\end{tabular}

Sumber: Data Primer Setelah Diolah,2018

Dari hasil perhitungan Net Benefit yang dikalikan dengan faktor diskonto (Discount Rate) sebesar $14 \%$ di peroleh nilai NPV sebesar Rp.232.480.306,. Dengan nilai NPV
e-ISSN : 2621-7236

p-ISSN : 1858-134X

RP.232.480.306, maka usaha ini dinyatakan layak untuk diusahakan, karena nilai NPVnya positif.

\section{Net Benefit Cost Ratio (net B/C)}

Net $B / C$ merupakan perbandingan antara jumlah NPV positif dan NPV negative. Berdasarkan perhitungan NPV pada tabel 7 dapat diketahui bahwa NPV positif sebesar Rp.1.422.480.306, dan nilai NPV negative sebesar Rp.1.190.000.000,. Sehingga Net Benefit Cost Ratio (Net B/C) dapat dihitung sebagai berikut:

$$
\text { Net } \begin{aligned}
\mathrm{B} / \mathrm{C} & =\frac{1.422 .480 .306}{1.190 .000 .000} \\
& =1,19
\end{aligned}
$$

Perhitungan tersebut menghasilkan nilai Net $\mathrm{B} / \mathrm{C}$ sebesar 1,19 , dimana Net $\mathrm{B} / \mathrm{C}>1$ maka Usaha Penggilingan Padi "Cahaya Ummul" ini layak untuk diusahakan.

\section{Payback Period}

Payback Period merupakan metode yang paling sederhana dan banyak dipakai didalam mengukur tingkat kewajaran atau kelayakan suatu proyek investasi. Metode ini tidak memasukkan unsur nilai waktu uang didalam perhitungannya. Periode menutup pengeluaran investasi yang dilakukan. Berikut ini dapat dilihat perhitungan

Payback Period yaitu:

Perhitungan investasi $\quad$ :Rp.1.190.000.000

Aliran kas tahun pertama :Rp.382.820.440

Aliran kas tahun kedua $\quad$ :Rp.399.632.000

Aliran kas tahun ketiga $\quad$ :Rp.413.959.500

$P P={ }_{\text {keuntungan }}^{\text {investasi }} \times 1$ tahun $x \frac{407.547 .560}{413.959 .500}=0,98$

Periode Bulan $\quad=0,98 \times 12$

$$
=11,76 \text { bulan }
$$

Hasil perhitungan sisa investasi yang telah dikurangkan dan aliran kas masuk pada tahun ke-2 yaitu $\mathrm{Rp} 407.547 .560$ dan jumlah aliran kas tahun ke-3 sebesar Rp 413.959.500 diperoleh sisa waktu sebesar 0,98 tahun atau 11 bulan 23 hari. sehingga perhitungan diatas diketahui payback period adalah 2 tahun 11 bulan.

\section{Internal Rate Of Return (IRR)}

Metode Internal Rate Of Return (IRR) merupakan metode menghitung tingkat bunga yang menyamarkan nilai pada awal investasi. Bila tingkat bunga ini lebih besar dari tingkat bunga yang disyaratkan maka investasi termasuk menguntungkan dan apa bila lebih kecil dari tingkat bunga yang syaratkan maka investasi tersebut tidak menguntungkan. Perhitungan IRR disajikan dalam Tabel 4. 
Tabel 4. Aliran Kas Operasional Pada Tingkat Bunga Antara 21\% dan 22\% (IRR) Pada Usaha Penggilingan Padi Cahaya Ummul Di Kecamatan Galang Kabupaten Tolitoli

\begin{tabular}{ccc}
\hline Tahun & Net Benefit & DF $(21 \%)$ \\
\hline 0 & $(1.190 .000 .000)$ & 1.000000 \\
1 & 382.820 .440 & 0.826446 \\
2 & 399.632 .000 & 0.683013 \\
3 & 413.959 .500 & 0.564474 \\
4 & 418.550 .200 & 0.466507 \\
5 & 446.571 .500 & 0.385543 \\
\hline Jumlah & 871.533 .640 \\
Sumber: Data Primer Setelah Diolah, 2018 \\
$\begin{aligned} \text { IRR }= & 21 \%+\frac{432.761}{432.761-(25.580 .706)}(22 \%-21 \%) \\
& =21 \%+\frac{432.761}{26.013 .467}(1 \%) \\
& =21 \%+0.016 \% \\
& =21,016 \%\end{aligned}$
\end{tabular}

Hasil perhitungan diatas menunjukkan bahwa tingkat pengembalian internal (IRR) yakni sebesar 21,016\% lebih besar dari interst rate (tingkat bunga bank) yang berlaku yaitu $14 \%$ saat dilakukan evaluasi, ini berarti usaha penggilingan padi "Cahaya Ummul" layak untuk diusahakan.

\section{Kesimpulan}

Analisis payback period atau lama waktu investasi yang akan dikembalikan terjadi pada waktu 9 tahun 3 bulan, analisis NPV atau arus kas yang diperkirakan pada masa yang akan datang yang didiskontokan pada saat ini yaitu sebesar 14\% dengan jumlah NPV sebesar 232.480.306 >0 (positif), analisis Net B/C yaitu nilai perbandingan antara jumlah PV net benefit yang positif dengan jumlah PV net benefit yang negatif didapatkan nilai sebesar $1,19>1$, dan analisis IRR yaitu tingkat efisien dari suatu investasi sebesar 21,016 $\%$ dengan suku bunga sebesar $14 \%$ saat dilakukan evaluasi. Jadi usaha ini dinyatakan layak untuk diusahakan.

\section{Daftar Pustaka}

Allidawati dan B.Kustianto. 1989. Metode uji mutu beras dalam program pemuliaan padi. http/www.googel.co, diakses pada tanggal 26 Maret 2017

Asmawati. (2009). Analisis Keseimbangan Massa pada Pabrik Penggilingan Gabah UD. Jakarta: Universitas Indonesia.

BPS,2007., Jakarta Dalam Angka, Jakarta.

\begin{tabular}{rrr}
\multicolumn{1}{c}{$\mathrm{Npv}^{\prime}(2 \times 3)$} & \multicolumn{1}{c}{$\mathrm{DF}^{\prime \prime}(22 \%)$} & \multicolumn{1}{c}{$\mathrm{Npv}^{\prime \prime}(2 \times 5)$} \\
$(1.190 .000 .000)$ & 1.000000 & $(1.190 .000 .000)$ \\
$316.380 .421,3$ & 0.819672 & $313.787 .195,6$ \\
$272.953 .851,2$ & 0.671862 & $268.497 .554,7$ \\
$233.669 .374,8$ & 0.550707 & $227.970 .394,3$ \\
$195.256 .598,1$ & 0.451399 & $188.933 .141,7$ \\
$172.172 .515,8$ & 0.369999 & $165.231 .008,4$ \\
\hline 432.761 & & $(25.580 .706)$ \\
\hline
\end{tabular}

BPS,2015.,Tolitoli Dalam Angka, Tolitoli.

BPS,2015.,Sulteng Dalam Angka, Sulteng.

Bishop dan Toussaint, 1986. Pengantar Analisa Ekonomi Pertanian. Jakarta: Mutiara Sumber Widya.

Choliq Abdul (2001:49). Pengertian payback period. http://nanang budianas.blogspot.com/2013/02/pengertianpaybackperiods.html. [16April 2014]

Choliq. Abdul, Wirasasmita, Rivai dan Hasan. Sumarna, 1999. Evaluasi Proyek (suatu pengantar). Bandung: Pionir Jaya.

Damardjati, D.S. 1988. Struktur kandungan gizi beras. Balai Penelitian dan Pengembangan Pertanian, Pusat Penelitian dan Pengembangan Pertanian, Pusat Penelitian dan Pengembangan Tanaman Pangan. Bogor.

Dinas Pertanian Kabupaten Tolitoli, 2017

Ditjen Bina Pengelolahan Dan Pemasaran Hasil Pertanian. 2009. proses pembangunan usaha Penggilingan Padi. Jakarta: Deptan.

Handaka, 2005. Inovasi Mekanisasi Pertanian Berkelanjutan. Jakarta: Pustaka Jaya

Jakes Sito. 2011. Cara Pengeringan Padi. Bandung: Wordpress

Kasmir dan Jakfar. 2004. Studi Kelayakan Bisnis. Jakarta: Predana Media

Nugraha, U.S., S.J.Munarso, Suismono dan A. Setyono. (1998). Tinjauan Tentang Rendemen Beras Giling Dan Susut PaskaPanen: Rendemen Beras Giling, Susut Dan Pemecahannya. Penelitian Tanaman Padi Bogor. 
e-ISSN : 2621-7236

Jurnal Agrotech 9 (2) 60-65

p-ISSN : 1858-134X

Ritonga, A. W. 2008. Bogor: Penggilingan Padi. IPB

Soekartawi, 1991. Teori Ekonomi Produksi. Jakarta: UI Press

Saragih, 1999. Kumpulan Pemikiran Agribisnis. Paradikma Baru Pembangunan Pertanian. Jakarta: Pustaka Wirausaha.

Singarimbun, M, dan Effendi, S. 1989. Metode Penelitian Survai, Edisi Revisi, Jakarta: LP3ES.

Soekartawi, 1995. Analisis Usahatani. Jakarta: UI Press

Waries, A. 2006. Teknologi Penggilingan Padi. Jakarta: PT Gramedia Pustaka Utama. Jakarta. 